\title{
People Management Trends of Australian Public Service Middle Managers
}

\author{
Nicky Antonius \\ Southern Cross Business School, Southern Cross University \\ Southern Cross Drive, Bilinga, Queensland 4225, Australia \\ Email: n.antonius.11@scu.edu.au
}

\begin{abstract}
Change is more pervasive in the Australian Public Service than ever. Taking the number of vacancy advertisements as an indication, the more stable periods of 2008 and 2009 were followed by vast expansions in 2010 and 2011, but suddenly downturned into drastic cuts in 2012 and 2013. Public service middle managers have been singled out as the most susceptible to organizational resizing since the days of business process re-engineering movement in the 1980 s and 1990s, when hierarchical organizational structures were significantly flattened. This paper investigates the longitudinal trends for middle managers (Executive Level positions) in the APS, in terms of employment vacancies, appointments, and retirements.
\end{abstract}

Keywords: Public sector management, Government management, Human Resources, People management, Employment trends, Industrial relations, Employee turnover, Public service career.

\section{Introduction}

Change is pervasive in today's organizations and the public sector is not exempt. This is all the more apparent when Australian governments from both sides of the aisle have implemented sharp cuts to public service employment budgets. The 2013-14 Australian Federal budget released by Labor in May 2013 aimed to shave the number of middle managers to the tune of $\$ 580$ million over four years. ${ }^{1}$ When the Liberal government took office later that year, one of its election promises was to cut over 10,000 public servants. $^{2}$ The New South Wales state government targeted $20 \%$ reduction from the ranks of senior and middle managers within three years. ${ }^{3}$ Governments in other parts of the world such as those in the United Kingdom and New Zealand have also tightened the belt on their respective public sectors, specifically those in middle management positions. ${ }^{4,5}$ Improved financial management of the public purse was consistently cited as the main driving factor in these instances.

Middle managers have been singled out as the most susceptible to organizational resizing since the days of business process re-engineering movement in the 1980s and 1990s, when hierarchical organizational structures were significantly flattened. ${ }^{6,7}$ On the other spectrum, Baum $^{4}$ and Carlstrom ${ }^{8}$ concluded that middle managers continue to play a critical role in managing operations and delivering outcomes. Middle managers remain instrumental in implementing and delivering policies, becoming the differentiating factor between low performing and high performing organizations. ${ }^{9}$ Middle managers realize strategic initiatives into operational targets and processes. ${ }^{10}$ 
The Australian Public Service (APS) is specifically examined further in this paper as the Australian Federal civil service. The research question for this paper is: What are the longitudinal trends for middle managers (Executive Level positions) in the APS, in terms of employment vacancies, appointments, and retirements?

\section{Background}

Middle managers are defined as those in supervisory positions between first-level supervisors and senior executives. ${ }^{11}$ In the Australian Federal public service, middle managers can be reflected as those occupying the Executive Level (EL) 1 and 2 positions, who supervise Australian Public Service (APS) level 1 to 6 professionals, and report to Senior Executive Service (SES) officers. ${ }^{12}$ Figure 1 displays the classification structure.

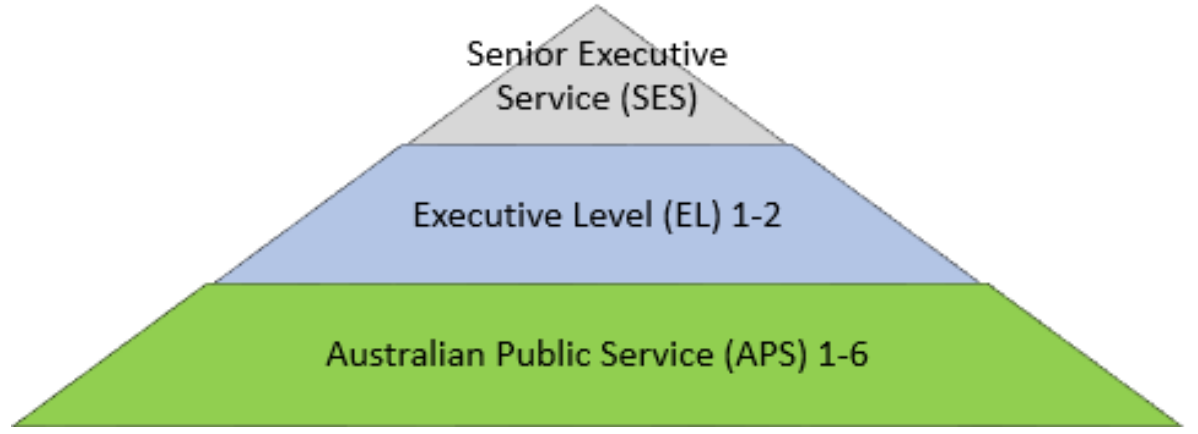

Fig. 1. Australian Public Service Classification Structure ${ }^{12}$

The APS Commission ${ }^{13}$ indicated that the number of middle managers at the Executive Level positions have been at the highest point throughout the past decade, justifying a rationale for the restrictive conditions described earlier. Balancing these circumstances with the leadership role of middle managers warrant an investigation into the employment trends of middle managers in the Australian Federal public service, also called the APS.

Environmental drivers to the public service are diverse, induced by both global as well as domestic drivers. ${ }^{14}$ Today's public service is facing complex adaptive challenges, which have no clear answers and no easy solutions, resulting in policy being highly contested. ${ }^{15}$ This intricate environment challenges middle managers to display resilience with highly developed emotional intelligence in providing robust and impartial advice. ${ }^{14}$ Australia, like a handful of countries around the world, is facing an ageing workforce demographics with around $23 \%$ projected to be over 65 years old in 2050. ${ }^{16}$ Public service middle managers have to get the most out of diversity, catering to different learning and communication styles, different work-life balance needs and diverse preferences on how to recognize staff contributions. ${ }^{17}$ Regionally, the Asian Century demands Australian public servants to have the relevant strategic vision, political nous and interpersonal skills to assist their organizations to adapt to new dynamics and challenges. ${ }^{18}$ Heightened expectations of productivity means Australian public service leaders need to display strong relationship management skills to reconcile competing priorities among partners. ${ }^{19}$

In addition, New Public Management (NPM) tenets demand the delivery of personalized services that meet every citizen's unique needs while being delivered en masse. ${ }^{20}$ For example, the strict reductions of the public service described earlier are consistent with NPM which emphasizes on greater discipline and parsimony in resource use, typically realized through cutting direct labor costs and doing more with less. ${ }^{21}$ In addition, NPM also recommends greater disaggregation to create manageable units and more hands-on, accountable professional management in the public sector, which in turn led to a substantial increase in middle managers during the last two decades. ${ }^{21-23}$

\subsection{Role of Middle Managers}

The role of middle managers in the Australian civil service is outlined by the APS Commission ${ }^{24}$ as follows:

- Operate under broad direction in a highly complex environment 
- Exercise a significant degree of independence and leadership

- Develop strategy and practices to achieve agency objectives

- Provide high level advice to senior management and Ministers

- Coordinate highly complex programs with strategic significance

- Establish strong relationships with key stakeholders, and

- Lead a work team or teams.

Middle managers are responsible for a wide variety of roles in the public service. As the primary medium between senior executives and staff, middle managers have an integrative role for downward and upward communication about strategy formulation and implementation. ${ }^{25}$ Middle managers translate overall strategic goals to staff's personal goals and objectives. ${ }^{26}$, 27 Middle managers in the APS are expected to contribute to strategic directions set by the senior executives, develop long-term plans and implement operational strategies aimed at achieving specific agency objectives. ${ }^{24}$

As a result, middle managers are crucial in promoting a climate of change and continuous improvement in leading their staff to achieve organizational outcomes. Scholars see middle managers articulating and changing organizational cultures to achieve organizational flexibility. ${ }^{10,28,29}$ This climate of regular re-shaping of organizational culture understandably creates friction in the role of middle managers. Caught between the directives of their seniors on one hand and the demands of their employees on the other, middle managers have been described as the toothpaste in the tube squeezed between the upper and lower levels of organizational demand. ., $^{30}$

Middle managers were once staff members, having worked their way up through the career ladder, so it is reasonable to expect a sense of familiarity with how the employees work and think. ${ }^{31}$ Subsequently, prior studies show that middle managers are in the best position to develop their staff through on-the-job training and experiential learning to enhance their employees' competence. $^{32-34}$

\subsection{Leading from the middle}

The predicament facing middle managers being the buffer between senior executives and their staff have been described colorfully by scholars ranging from being the filling in the sandwich, ${ }^{35}$ piggy in the middle, ${ }^{36}$ and linking pins. ${ }^{37}$ Indeed there is a clear and present danger for middle managers who are unsuccessful in thriving from this paradox; failing middle managers either face reprimands from their superiors or undermined by those they supposedly lead. ${ }^{38}$ Taking these viewpoints into account, it is clear that middle managers need to master the art of leading from the middle. ${ }^{39}$

With these inherent pressures, Gabel ${ }^{38}$ recommended several practical strategies that middle managers can implement to survive. Table 1 summarizes the recommendations.

Table 1. Strategies to extricate oneself from the middle ${ }^{38}$

\begin{tabular}{|c|c|c|}
\hline Step & Strategy & Recommendation \\
\hline \multirow[t]{3}{*}{1} & \multirow{3}{*}{$\begin{array}{l}\text { Assess } \\
\text { and } \\
\text { Evaluate }\end{array}$} & $\begin{array}{l}\text { Clarify the issue at hand, both stated } \\
\text { and unstated }\end{array}$ \\
\hline & & Clarify and assess personal values \\
\hline & & $\begin{array}{l}\text { Clarify stated and unstated agendas of } \\
\text { supervisors, staff members and } \\
\text { external stakeholders }\end{array}$ \\
\hline \multirow[t]{5}{*}{2} & \multirow{5}{*}{$\begin{array}{l}\text { Decision } \\
\text { and } \\
\text { Action }\end{array}$} & $\begin{array}{l}\text { Decisions based on organization } \\
\text { mission and goals }\end{array}$ \\
\hline & & $\begin{array}{l}\text { Decisions which are consistent with } \\
\text { personal values and goals }\end{array}$ \\
\hline & & $\begin{array}{l}\text { Decisions to support allies when } \\
\text { possible }\end{array}$ \\
\hline & & $\begin{array}{l}\text { Decisions to create allies from } \\
\text { adversaries when possible }\end{array}$ \\
\hline & & $\begin{array}{l}\text { Decisions to incorporate as many } \\
\text { needs as possible }\end{array}$ \\
\hline \multirow[t]{2}{*}{3} & \multirow[t]{2}{*}{$\begin{array}{l}\text { Follow } \\
\text { through }\end{array}$} & $\begin{array}{l}\text { Explain to supervisors, staff and } \\
\text { external stakeholders of rationale for } \\
\text { decision }\end{array}$ \\
\hline & & $\begin{array}{l}\text { Outline future options for their needs } \\
\text { to be met when possible }\end{array}$ \\
\hline \multirow[t]{2}{*}{4} & \multirow[t]{2}{*}{$\begin{array}{l}\text { Future } \\
\text { course }\end{array}$} & $\begin{array}{l}\text { Remember agendas expressed during } \\
\text { this decision-making cycle }\end{array}$ \\
\hline & & $\begin{array}{l}\text { Re-contact those involved when their } \\
\text { agendas can be fulfilled }\end{array}$ \\
\hline
\end{tabular}

Carlstrom $^{8}$ described three interconnected strategies for middle managers to lead from the middle. Firstly, middle managers can slide downwards by becoming a defense counsel for staff members by taking on advocacy roles to ally and create a unifying bond with their staff. $^{40}$ During cutbacks, middle managers slide upwards by being the employer's representative to negotiate, explain and when necessary, share an 
unpleasant message of separation to employees. ${ }^{41}$ Lastly, when the management burden is too great, or when middle managers are forced into an isolated position, they can choose to slide out to escape conflictfilled environment by staying away and laying low. ${ }^{42}$ An avoidance strategy may be the appropriate course of action where the conflicts are too numerous, or if there is a lack of management tools and skilled staff to immediately deal with the situation. ${ }^{43}$ With time and more changes, new executive directions, controls and procedures may present opportunities for middle managers to re-engage the situation with the appropriate means. ${ }^{8}$

The quandary has influenced the shape of contemporary leadership development programs. For example, Day ${ }^{44}$ devised a program that encourages participants to think and act in new ways, thus building capacity in anticipation of unforeseen challenges. Similar principles are also implemented by the APS Commission $^{45}$ for middle managers in the Australian Federal civil service.

\subsection{Efficiency as a driving factor for public service reduction}

The concept of efficiency has been frequently touted as an omnipotent reason to warrant reductions in the size of the public service. Some examples in recent memory for the APS include:

- A 'razor gang' in 2007 aimed to create $\$ 3$ billion in administrative savings ${ }^{46}$

- Efficiency dividend, the annual funding reduction for the running costs of an agency, was commonly set around $1 \%$, but increased to $3.25 \%$ in $2008-09$ and $4 \%$ in $2012-13^{47}$, and

- A National Commission of Audit ${ }^{48}$ was established as a special measure to review the efficiency of the Commonwealth government.

There is also a recognized trend of exceptional and above the norm efficiency programs levied on the public service following a change in governments. Upon taking office in 1996, the Howard government downsized the APS by almost 30,000 staff $(21 \%) .{ }^{13,49}$ A 'razor gang' was commissioned by the Rudd government as it took office in $2007 .{ }^{46}$ Within weeks of winning election in 2013, the Abbott government implemented interim arrangements that saw all APS recruitment activities requiring the centralized approval of the APS
Commission $^{50}$, in addition to the National Commission of Audit ${ }^{48}$

In rare circumstances, an efficiency review may also lead to an increase in the size of the public service. An example is the Gershon report which recommended the reduction of information and communication technology (ICT) contractors by $50 \%$ within two years and in substitute, increase the number of permanent ICT staff, to save approximately $\$ 100$ million. $^{51}$

These examples indicate efficiency is consistently associated with reduction of financial outlay for the public purse. With a numeric economic goal as the golden objective, these initiatives may cause undesired effects to the diversity and quality of services delivered to the public. In other words, the manner in which these savings can be achieved are often left unstated, thus open for interpretation and may cause unintended, sometimes far-reaching, detriment. Middle managers, with their relatively higher pay rates than staff members, are often targeted in these efficiency programs to minimize the impacted number of staff. ${ }^{52}$

These efficiency measures were questioned by Stone $^{53}$ as to whether they are necessary. Comparisons based on $\mathrm{OECD}^{54}$ findings indicated that Australia was the ninth most effective government out of the 34 countries in terms of tax revenues. Stone ${ }^{53}$ also attempted a comparison between the public and private sectors, and based on limited data available, concluded them to display similar levels of efficiency. On these findings, Australia's public service compared favorably, and operating on fewer resources, than similar countries around the world. ${ }^{53}$

It is arguable that the series of stringent efficiency programs consecutively applied to the APS over the past few years have achieved reasonable efficiency and reached an inflection point. If so, then future efficiency programs may need to be applied with more specific parameters, such as determining efficiencies based on staff performance levels, or retraining the excess workforce to deliver future work programs deemed as a national priority.

\section{Research Question}

The background outlined how middle managers continue to be important in the public service with high expectations of performance and leadership, but frequently faced with tightening economic conditions and efficiency programs. The APS is specifically 
examined further in this paper as the Australian Federal civil service. The research objective for this paper therefore is to investigate employment trends of middle managers in the APS over the past several years.

The Australian Public Service Commission publishes several annual industry-wide snapshots on the state of the APS. Although these sources are informative, they are summarized on a yearly account and do not adequately focus on middle managers. It therefore remains a research gap to explore the longitudinal trends of APS middle managers, both for seasonal trends in a given year, as well as over several years. The research question for this paper is: What are the longitudinal trends for middle managers (Executive Level positions) in the APS, in terms of employment vacancies, appointments, and retirements?

\subsection{Data Collection}

The target population for this research is Executive Level or equivalent positions in the APS. The research focuses on the past six years as a sampling frame, which includes data on Executive Level employment trends between 2008 and 2013. The timeframe is chosen to maintain the currency of findings, but also outline the impact of efficiency programs in recent memory, as outlined earlier.

The principal data analyzed in this paper is derived from the Australian Public Service Gazette, as published on the APSJobs website. The Gazette is released on a weekly basis with information about: ${ }^{55}$

- Employment vacancies available in the APS

- The filling of a vacancy through engagement, promotion or movement, and

- Retirement or termination of an APS employee.

Weekly releases of APSJobs published between January 2008 and December 2013 were collected in January 2014 for this paper. Significant data cleansing and re-formatting were undertaken to ensure the gazettal publications are suitable for further analysis.
The following industry-wide information on the APS were relied on as supporting sources to paint the landscape:

- State of the Service Reports, annual assessments of the APS by the APS Commission ${ }^{13}$ in accordance with section 44 of the Public Service Act 1999

- APS Statistical Bulletin, annual quantitative snapshots of Federal public service employment APS Commission ${ }^{56}$ and

- The Australian Public Service Employment Database Internet Interface (APSEDii), a web interface that produces quantitative summaries on the APS. ${ }^{57}$

\subsection{Data Collation and Analysis}

In total, there were over 300 individual files which represented the weekly APS Gazette releases between 2008 and 2013. The data was re-formatted and collated in a Microsoft Access database according to the notice types, which include vacancy advertisement, engagement, promotion, movement, retirement and corrigenda. Descriptive data analyses were conducted primarily on Microsoft Excel which facilitates easy tabulation and charting.

\section{Findings}

Mannheim $^{52}$ reported that the number of middle managers in the APS increased exponentially in the past few years. Observing the totals of APSEDii reveals that for the financial year ending in 2013, there were 43,225 Executive Level and equivalent employees out of 167,257 public servants in the APS (approximately $26 \%) .{ }^{57}$ It is apparent that while the number of Executive Level staff have increased over the past six years, the rise is specifically in the Executive Level 1 range in expense of a decrease in the APS Levels. The distribution of Executive Level 2 and Senior Executive Service have remained consistent. The distribution of classifications for the Australian Public Service between 2008 and 2013 is shown in Table 2.

Table 2. Distribution of Classifications in APS 2008-2013

\begin{tabular}{lccccc}
\hline $\begin{array}{l}\text { Distribution of Classifications in } \\
\text { Australian Public Service }\end{array}$ & $\mathbf{2 0 0 8}$ & $\mathbf{2 0 0 9}$ & \multirow{2}{*}{$\mathbf{2 0 1 0}$} & $\mathbf{2 0 1 1}$ & $\mathbf{2 0 1 2}$ \\
\hline Total number of staff & 159,738 & 161,769 & 164,351 & 166,152 & 168,164 \\
APS Level & $76 \%$ & $75 \%$ & $74 \%$ & $73 \%$ & $72 \%$ \\
Executive Level 1 & $15 \%$ & $16 \%$ & $16 \%$ & $17 \%$ & $18 \%$ \\
Executive Level 2 & $7 \%$ & $8 \%$ & $8 \%$ & $8 \%$ & $8 \%$ \\
Senior Executive Service & $2 \%$ & $2 \%$ & $2 \%$ & $2 \%$ & $2 \%$ \\
\hline
\end{tabular}

Published by Atlantis Press

Copyright: the authors 
The classifications also reflect an approximation of hierarchical structures. Staff on APS Levels commonly report to Executive Level 1, who would on-report to Executive Level 2 positions, and ultimately reporting to Senior Executive Service officers. While the supervisory ratio for Executive Level 2 and Senior Executive Service remained consistent over six years at managing two Executive Level 1 and five Executive Level 2 respectively, Executive Level 1 officers have decreasing supervisory ratio from five APS to four APS, thus indicating a higher number of Executive Level 1 officers in comparison to APS staff. Table 3 displays the average supervisory ratio for each of the leadership levels.

Table 3. Average Supervisory Ratio in APS 2008-2013

\begin{tabular}{lcccccc}
\hline Average Supervisory Ratio in APS & $\mathbf{2 0 0 8}$ & $\mathbf{2 0 0 9}$ & $\mathbf{2 0 1 0}$ & $\mathbf{2 0 1 1}$ & $\mathbf{2 0 1 2}$ & $\mathbf{2 0 1 3}$ \\
\hline Executive Level 1 & 5 APS & 5 APS & 5 APS & 4 APS & 4 APS & 4 APS \\
Executive Level 2 & 2 EL1 & 2 EL1 & 2 EL1 & 2 EL1 & 2 EL1 & 2 EL1 \\
Senior Executive Service & 5 EL2 & 5 EL2 & 5 EL2 & 5 EL2 & 5 EL2 & 5 EL2 \\
\hline
\end{tabular}

\subsection{Trends in Vacancy Advertisements}

Vacancies in the APS are advertised in the APSJobs website as a norm. Vacancy advertisements can be an indication of whether the APS is expanding or reducing. In total, there were 71,677 employment opportunities in the APS as advertised in APSJobs between 2008 and 2013, out of which there were 22,909 Executive Level or equivalent positions $(32 \%)$.

Year-by-year comparison of Executive level vacancies reveals several trends. The total number of advertised vacancies peaked in 2011 and has been on a steep downward slide since. The proportion of Executive Level positions advertised increased from $30 \%$ in 2008 to an average of $32 \%$ between 2009 and 2012. Although the total number of vacancies in 2013 is at historic lows, nearly half of that in 2008, but the proportion of Executive Level positions jumped to $35 \%$. It may be reasonable to suggest that the consecutive efficiency programs applied to the APS have reduced job vacancies at the APS and Senior Executive levels, more so than the Executive Levels. Table 4 details the year-by-year proportion of Executive Level vacancies.
Table 4. Year-by-Year Proportion of Executive Level Vacancies in APS 2008-2013

\begin{tabular}{cccc}
\hline $\begin{array}{c}\text { Executive Level } \\
\text { Vacancies in } \\
\text { APS }\end{array}$ & $\begin{array}{c}\text { Executive } \\
\text { Level } \\
\text { Vacancies }\end{array}$ & $\begin{array}{c}\text { All } \\
\text { Vacancies }\end{array}$ & Percent \\
\hline 2008 & 4,212 & 14,007 & $30 \%$ \\
2009 & 3,773 & 11,728 & $32 \%$ \\
2010 & 4,812 & 14,652 & $33 \%$ \\
2011 & 4,858 & 15,421 & $32 \%$ \\
2012 & 3,006 & 9,422 & $32 \%$ \\
2013 & 2,248 & 6,447 & $35 \%$ \\
Total & 22,909 & 71,677 & $32 \%$ \\
\hline
\end{tabular}

The seasonal trend for Executive Level vacancies is a steady increase of advertisements through the year. In four consecutive years (2008, 2009, 2010, and 2011), the number of Executive Level vacancies started modestly in Q1, and climbed upwards for the remainder of the year. The highest numbers of Executive Level vacancies were seen in Q4 of 2011 and 2010 respectively. However this trend stopped in the last two years. 2012 saw a decline of vacancies throughout the year, leading to a drastic drop in Q4 2013, reflecting the interim centralized employment arrangements applied by the Abbott government in late $2013 .{ }^{50}$ Table 5 breaks down the figures on a quarterly basis.

Table 5. APS Executive Level Vacancies 2008-2013

\begin{tabular}{lcccccc}
\hline EL Vacancies in APS (Quarterly) & $\mathbf{2 0 0 8}$ & $\mathbf{2 0 0 9}$ & $\mathbf{2 0 1 0}$ & $\mathbf{2 0 1 1}$ & $\mathbf{2 0 1 2}$ & $\mathbf{2 0 1 3}$ \\
\hline Q1 & 927 & 847 & 970 & 1,011 & 911 & 645 \\
Q2 & 973 & 792 & 1,229 & 1,229 & 794 & 736 \\
Q3 & 1,060 & 975 & 1,184 & 1,188 & 635 & 641 \\
Q4 & 1,252 & 1,159 & 1,429 & 1,430 & 666 & 226 \\
Total & 4,212 & 3,773 & 4,812 & 4,858 & 3,006 & 2,248 \\
\hline
\end{tabular}




\subsection{Trends in Appointments}

The successful filling of a vacancy may arise from one of three employment decisions: ${ }^{58}$

- Engagement, hiring of a person not on the APS

- Promotion, appointing a current APS employee to a higher classification, or

- Movement, transfer of a current APS employee at the same classification.

Between 2008 and 2013, there were 142,309 recorded appointments in the APS. Well over half of appointments in Executive Level positions come about from promotions (57\%), while engagements and promotions are roughly equal for the other classifications (47\% and $43 \%$ respectively). The distribution indicates that only about a quarter of appointments (28\%) for Executive Level positions are awarded to those outside the APS. If the trend holds true, it is reasonable to suggest that an existing APS employee, with the appropriate competencies, is twice more likely to win an Executive Level appointment than those outside of the Service. The proportion concerning Executive Level positions is shown in Table 6.

Table 6. APS Executive Level Appointments 2008-2013

\begin{tabular}{lccc}
\hline \begin{tabular}{c} 
Executive Level \\
Appointments in \\
\multicolumn{1}{c}{ APS }
\end{tabular} & $\begin{array}{c}\text { Engage } \\
\text { ment }\end{array}$ & Promotion & Movement \\
\hline Executive Level & 9,322 & 19,312 & 5,218 \\
Positions & $(28 \%)$ & $(57 \%)$ & $(15 \%)$ \\
All Classifications & 67,513 & 60,401 & 14,395 \\
& $(47 \%)$ & $(43 \%)$ & $(10 \%)$ \\
\hline
\end{tabular}

Data from the Gazette also facilitates a frequency analysis where certain APS employees received multiple appointments within the timeframe analyzed. Analyzing those who were first engaged between 2008 and 2013 and subsequently received promotions within the same period, revealed 12,569 employees who fall under this category. Table 7 shows the distribution for those relating to Executive Level positions.
Table 7. Multiple Appointments relating to Executive Level positions in APS 2008-2013

\begin{tabular}{lccc}
\hline \multicolumn{1}{c}{$\begin{array}{c}\text { Multiple } \\
\text { Appointments }\end{array}$} & Number & $\begin{array}{c}\text { Average } \\
\text { Percent } \\
\text { of Total }\end{array}$ & $\begin{array}{c}\text { Length of } \\
\text { Service to } \\
\text { Promotion } \\
\text { (Months) }\end{array}$ \\
\hline $\begin{array}{l}\text { Engaged at APS and } \\
\text { Promoted to EL1 }\end{array}$ & 2,898 & $86 \%$ & 30 \\
$\begin{array}{l}\text { Engaged at EL1 and } \\
\text { Promoted to EL2 }\end{array}$ & 410 & $12 \%$ & 23 \\
$\begin{array}{l}\text { Engaged at EL2 and } \\
\text { Promoted to SES } \\
\text { Total Employees } \\
\text { with Multiple } \\
\text { Appointments }\end{array}$ & 48 & $1 \%$ & 24 \\
\hline
\end{tabular}

Table 7 corroborates the previous finding that the mainstream pathway (86\%) into Executive Level positions is commonly to be engaged at the APS Level and subsequently receiving a promotion to Executive Level 1 with an average length of service of 30 months. Engagements at Executive Level 1 positions, and subsequently receiving promotions, dropped significantly to $12 \%$, with an average length of service of 23 months. While engagements at Executive Level 2 with subsequent promotion to Senior Executive Service is the lowest at only $1 \%$, the average length of service is comparatively high at 24 months. The analysis of Senior Executive Levels is outside the scope of this paper, but the finding suggests that the Senior Executive Service requires significantly higher average length of service to reflect the required competencies.

\subsection{Trends in Retirements}

APS employees may exit their employment under various conditions. In some circumstances, such as when their employment is terminated under section 29 of the Australian Public Service Act 1999, or when accompanied with incentive payments, the event may be published on the Gazette as retirements. ${ }^{58}$

Between 2008 and 2013, there were 12,756 recorded retirements, 3,835 of which relate to those holding Executive Level positions. Retirements were more frequently opted on Q3 of each year, more so than any other parts of the year. 2012 by far, recorded the highest number of retirement of Executive Level officers (1,225 positions). In the following year, 2013, there were just nearly as many retirements ( 1,017 positions), but there was a definite spike in Q1, which was not seen in any 
other previous years. It was likely to be a continuation of the exodus between Q2 2012 and Q2 2013. The advent of the Abbott government in 2013 also induced an increase of retirements from Q3 to Q4, which did not happen for previous years. Table 8 charts the retirement trends for Executive Level officers between 2008 and 2013.

Table 8. Executive Level Retirements in APS 2008-2013

\begin{tabular}{lcccccc}
\hline EL Retirement in APS (Quarterly) & $\mathbf{2 0 0 8}$ & $\mathbf{2 0 0 9}$ & $\mathbf{2 0 1 0}$ & $\mathbf{2 0 1 1}$ & $\mathbf{2 0 1 2}$ & $\mathbf{2 0 1 3}$ \\
\hline Q1 & 30 & 30 & 47 & 45 & 68 & 305 \\
Q2 & 97 & 53 & 78 & 61 & 198 & 107 \\
Q3 & 201 & 212 & 263 & 114 & 510 & 269 \\
Q4 & 69 & 103 & 65 & 125 & 449 & 336 \\
Total & 397 & 398 & 453 & 345 & 1,225 & 1,017 \\
\hline
\end{tabular}

The number of retirements have significantly increased since 2012. Compared to 2011, retirements for both APS and Executive Level positions tripled in 2012. Although the totals tapered in 2013, the proportion of Executive Level retirements is at the highest for the past six years at $39 \%$ of all retirements. This is a marked increase from a range between $26 \%$ and $30 \%$ from 2008 to 2012 . The spread of retirements along the position classifications are shown in Table 9.

Table 9. Retirements by Classification in APS 2008-2013

\begin{tabular}{lllllll}
\hline Retirements in APS & $\mathbf{2 0 0 8}$ & $\mathbf{2 0 0 9}$ & $\mathbf{2 0 1 0}$ & $\mathbf{2 0 1 1}$ & \multicolumn{1}{c}{$\mathbf{2 0 1 2}$} & $\mathbf{2 0 1 3}$ \\
\hline APS (and equivalent positions) & 875 & 1,039 & 982 & 922 & 3,248 & 1,527 \\
EL (and equivalent positions) & 397 & 398 & 453 & 345 & 1,225 & 1,018 \\
SES (and equivalent positions) & 72 & 42 & 48 & 31 & 73 & 61 \\
Total & 1,344 & 1,479 & 1,483 & 1,298 & 4,546 & 2,606 \\
\hline
\end{tabular}

Lastly, the longitudinal data also facilitates the analysis of individuals who were engaged and later retired within the time period analyzed. Between 2008 and 2013, there were 813 individuals who fit this category. The figures indicate that the majority of those engaged and subsequently retired between 2008 and 2013 did so primarily at the same broad classifications.
The more significant finding however, is that these individuals form a very small proportion of the total retirements ( 813 out of $12,756,6 \%$ ). This indicates that the vast majority of retirees were engaged prior to 2008 . Table 10 shows the classifications at which they were engaged and later retired.

Table 10. Persons Engaged and later Retired from APS 2008-2013

\begin{tabular}{lccc}
\hline \multirow{2}{*}{ Retirements in APS } & \multicolumn{3}{c}{ Classification at Retirement } \\
\cline { 2 - 4 } & APS (and equivalent) & EL (and equivalent) & SES (and equivalent) \\
\hline APS (and equivalent positions) & 642 & 3 & - \\
EL (and equivalent positions) & 19 & 134 & 1 \\
SES (and equivalent positions) & - & 2 & 12 \\
\hline
\end{tabular}




\section{Discussion}

Change is more pervasive in the APS than ever. Taking the number of vacancy advertisements as an indication, the more stable periods of 2008 and 2009 were followed by vast expansions in 2010 and 2011, but rather suddenly downturned into drastic cuts in 2012 and 2013. The trends from the past six years suggest a twoyear period for each phase to transition to the next.

Overlaying trends of vacancy advertisement and retirement, it is clear that the rapid expansions in 2010 and 2011 were followed by the highest number of retirements in 2012 and 2013. Given the consecutive nature of these events, there would be a question whether these retirements consist of those staff recently recruited in the preceding years. The finding on Table 10 points to the fact that only $6 \%$ of retirees were engaged in the past six years, thus the majority of retirements in 2012 and 2013 consisted of staff with greater lengths of service. From this point, it is possible to infer that the APS is experiencing a generational change where those with medium to long term lengths of service are more likely to retire and great numbers were recruited during the 2010 and 2011 expansionary periods.

Specific to the recruitment of middle managers, well over half (57\%) of appointments to Executive Level positions came about from promotions, and another $15 \%$ from movements. This means that over two-thirds of Executive Level positions in the past six years were filled by staff members already employed in the APS. The causes for this to occur could be many, ranging from internal factors such as a selection culture that gravitates towards existing familiarity with the role and organization, to more external alternatives such as lesser interest shown from outside the APS. Further research is required to determine the influencing causes.

The findings also imply that promotions are four times more likely to occur for Executive Level positions than 'at-level' movements. One would assume that 'atlevel' candidates would have greater experience and familiarity of expectations levied at the Executive Level. Thus it is more reasonable to suggest that in the case for Executive Level vacancies, the interest to apply for 'at-level' positions in the APS is far less than those seeking promotions.

Based on the six-year data as a sample population, the average length of service for an APS staff member to win an Executive Level position is approximately at
30 months. The average reduces to roughly 24 months for further promotions up the ladder, but the sample sizes are also significantly smaller for the higher classifications, thus it is not likely to be as relatable to the wider population.

As previously described in earlier sections, there is a current and continuing push by governments to reduce middle managers in civil service, including the APS. Retirement at Executive Level positions is at the highest for the past six years (39\% of retirements in 2013). At the same time, Table 4 suggests that the proportion of Executive Level vacancies also spiked in 2013. The overlapping increases in both recruitment and retirement suggest that the need for middle managers in the APS has not receded and continue to exist, but it is possible there is a recalibration of middle managers' roles and positions to reflect more contemporary organizational objectives.

\section{Conclusion}

Austerity measures impact on the rise and fall of middle managers in the civil service. ${ }^{8}$ Efficiency measures in themselves create greater expectations of performance from middle managers on how to do more with less, but the impact is even greater when the efficiency programs are squarely targeting at middle managers first and foremost.

This paper analyses management trends of middle managers in the APS. By collating the weekly Public Service Gazette between 2008 and 2013, trends of vacancy advertisements, engagements, promotions, movements and retirements were analyzed in some detail. Among several findings, it is revealed that the proportion of Executive Level positions spiked in both retirement, as well as vacancy advertisements. Thus it is likely that there is a persistent need for middle managers in the APS despite the increasing retirement numbers. If the proportion of Executive Level retirements continue, it is reasonable to suggest that there would be a regeneration of Executive Level officers in the short to medium term future.

There are limitations to this research. The paper leveraged on data published in the Public Service Gazette, which may contain erroneous entries. There are also certain parts of the APS which do not publish their employment decisions, such as the Australian Security Intelligence Organization or the Australian Secret Intelligence Service, for legislative or security reasons. 
The paper presents further research opportunities in several areas. For example, the Gershon report, as previously discussed, drives the recruitment of Executive Level specialists in lieu of ICT contractors. ${ }^{51}$ The impact of this expectation to the overall employment trend of APS middle managers is an area in need of further research. Similar analytical approaches can also be conducted on employment trends in Australian State and Territory governments, or compared with civil services of other countries to contrast the APS with global standards.

In summary, efficiency programs are unavoidable and will continue to be levied on the public service. If preceding years can be used as a lesson, future efficiencies will certainly be deeper and more demanding to the civil service. A resounding obligation lies on the current cadre of middle managers to provide sound and independent advice to government on how efficiency programs can both achieve short-term financial objectives and maintain sustainability towards the future.

\section{References}

1. Markus Mannheim, Budget to target senior public servants, in Sydney Morning Herald. 2013: Sydney, NSW.

2. Phillip Coorey, Abbott government's rethink on jobs to blow budget, in The Australian Financial Review. 2013, Fairfax Media Publications Pty Ltd.

3. Anna Patty, Purge of NSW public servants to save $\$ 65$ million, in Sydney Morning Herald. 2013: Sydney, NSW.

4. Richard Baum, Don't pick on public sector middle managers, Dr Coleman, in The Guardian. 2013: London, UK.

5. Mark Ellis, Million public sector jobs to have disappeared under Coalition spending cuts before next election, in The Daily Mirror. 2013, MGN Ltd: London, UK.

6. S. Dopson and R. Steward, What is happenning to middle management? British Journal of Management, 1990. 1: pp. 3-16.

7. D. Jackson and J. Humble, Middle managers: new purposes, new directions. Journal of Development Management, 1994. 13(3): pp. 15-21.

8. E. D. Carlstrom, Middle managers on the slide. Leadership in Health Services, 2012. 25(2): pp. 90-105.

9. John Purcell and Sue Hutchinson, Bringing Policies to Life: The $v$ ital role of front line managers in people management. Executive Briefing Series. 2003, London, UK: Chartered Institute of Personnel and Development.

10. R. A. Burgelman, A model of the interaction of strategic behaviour, corporate context, and the co ncept of strategy. Academy of Management Review, 1983. 8(1): pp. 58-69.
11. A. Frohman and L. Johnson, The Middle Management Challenge: Moving from crisis to empowerment. 1992, New York, NY: McGraw-Hill.

12. APS Commission, Australian Public Service Classification Guide, Commission, A.P.S., Editor. 2013, Commonwealth of Australia: Canberra, ACT.

13. APS Commission, State of the Service Report 2012-

13, Commission, A.P.S., Editor. 2013, Commonwealth of Australia: Canberra, ACT.

14. APS Commission, APS Leadership and Core Skills Strategy 2012-13, Commission, A.P.S., Editor. 2013, Commonwealth of Australia: Canberra, ACT.

15. Ronald A. Heifetz, Marty Linsky, and Alexander Grashow, The Practice of Adaptive Leadership: Tools and Tactics for Changing Your Organization and the World. 2009, Cambridge, MA: Harvard Business Press.

16. Commonwealth of Australia, Australia to 2050:

future challenges, Department, A.-G.s., Editor. 2010, Commonwealth of Australia: Canberra, ACT.

17. S. Hannam and B. Yordi Engaging a MultiGenerational Workforce: Practical advice for government managers. 2011.

18. Department of the Prime Minister and Cabinet, Australia in the Asian Cent ury, Cabinet, D.o.t.P.M.a., Editor. 2011, Commonwealth of Australia: Canberra, ACT.

19. Janine O'Flynn, Organisational capabilities for managing external provision, in Rethinking public service delivery: Managing with external providers, Alford, J. and O'Flynn, J., Editors. 2012, Palgrave MacMillan.

20. S. Hajkowicz, H. Cook, and A. Littleboy, Our Future World: Global megatrends that will change the way we live (2012 revision). 2012, Canberra, ACT: CSIRO.

21. Christopher Hood, A Public Management for All Seasons? Public Administration Review, 1991. 69: pp. 3-19.

22. M. Noordegraaf and $M$. van der Meulen, Professional power play: organising management in health care. Public Administration, 2008. 86(4): pp. 1055-69.

23. C. Pollitt, The Essential Public Manager. 2003, Maidenhead: Open University Press.

24. APS Commission. Work Level Standard - Executive Level 2. Work Level Standards 2013 [cited 201410 January]; Available from: http://www.apsc.gov.au/publications-andmedia/current-publications/worklevel-standards/el2.

25. Galanou Ekaterini, A qualitative approach to middle managers' competences. Management Research Review, 2011. 34(5): pp. 553-575.

26. E. G. Breen, Middle management morale in 1980 s, in Middle managers in Europe, Livian, Y.F. and Burgoyne, J.G., Editors. 1984, Routledge: London, UK.

27. H. Smith, Making managerial decisions: The role of intuition and emotion. Academy of Management Executive, 1987. 1: pp. 57-64.

28. K. Ishikawa, What is IQC? The Japanese way, in Middle managers in Europe, Livian, Y.F. and Burgoyne, J.G., Editors. 1985, Routledge: London, UK.

29. A. Wilkinson, T. Redman, and E. Snape, Quality and the Manager, in Middle managers in Europe, Livian, Y.F. and Burgoyne, J.G., Editors. 1993, Routledge: London, UK.

30. L. Holden and I. Roberts, The depowerment of European middle managers: challenges and uncertainties. Journal of Managerial Psychology, 2004. 19: pp. 269-87. 
31. Q. N. Huy, In praise of middle managers. Harvard Business Review, 2001(September): pp. 72-79.

32. C. Handy, The Age of Unreason. 1990, Boston, MA: Harvard Business School Press.

33. L. R. Sayles, Doing things right: A new imperative for middle manager. Organisational Dynamics, 1993(Spring): pp. 5-14.

34. B. L. Wisdom and D. K. Benton, Manager as a Leader. 1990, London, UK: Routledge.

35. T. McConville and L. Holden, The filling in the sandwich: HRM and middle managers in the health sector. Personnel Review, 1999. 28(5/6): pp. 406-424.

36. T. McConville, Devolved HRM responsibilities, middle managers and role dissonance. Personnel Review, 2006. 35(6): pp. 637-653.

37. G. Currie and S. Procter, Exploring the relationship between $H R$ and middle managers. Human Resource Management Journal, 2001. 11(3): pp. 53-69.

38. Stewart Gabel, Leading from the middle: Surviving the squeeze of apparently irreconcilable forces. Leadership \& Organisation Development Journal, 2002 . 23(7): pp. 361-371.

39. Stewart Gabel, Leaders and Health care organisational change: Art, Politics and Process. 2001, New York, NY: Kluwer Academic/Plenum Publishers.

40. J. Berlin and E. D. Carlstrom, The 90 second collaboration - a critical study of collaboration exercises at extensive accident sites. Journal of Contingencies and Crisis Management, 2008. 16(4): pp. 177-185.

41. C. Hales, Mowing down the line, the shi fting boundary between middle and first-line management. Journal of General Management, 2006. 32(2): pp. 31-55.

42. D. Farrell, Exit, voice, loyalty, and neglect as responses to job dissatisfaction. A multidimensional scaling study. Academy of Management, 1983. 26(4): pp. 596-607.

43. V. C. Garcia, Putting conflict management into practice: a nu rsing case stu dy. Journal of Nursing Management, 2006. 14: pp. 201-206.

44. D. Day, Leadership development: A review in context. Leadership Quarterly, 2001. 11(4): pp. 581-613.

45. APS Commission. Career Development Assessment Centre (CDAC). 2013 [cited 201415 January]; Available from: http://www.apsc.gov.au/learn/leadership/cdac.

46. Karen Barlow, Rudd to take razor gang to public service, in Australian Broadcasting Corporation News. 2007, Australian Broadcasting Corporation: Canberra, ACT.

47. Nicholas Horne, The Commonwealth efficiency dividend: an overview, Services, D.o.P., Editor. 2012, Commonwealth of Australia: Canberra, ACT.

48. National Commission of Audit. National Commission of Audit. 2013 [cited 201415 January]; Available from: http://www.ncoa.gov.au/.

49. Chris Johnson, Abbott can't guarantee he would keep department heads, in Sydney Morning Herald. 2013, Fairfax Media Pty Ltd: Sydney, NSW.

50. APS Commission, Interim arrangements for APS recruitment, Commission, A.P.S., Editor. 2013, Commonwealth of Australia: Canberra, ACT.

51. P. Gershon, Review of the Australian government's use of $i$ nformation and communication technology, Deregulation, D.o.F.a., Editor. 2008, Commonwealth of Australia: Canberra, ACT.
52. Markus Mannheim, Concerns over bureaucracy's army of midd le managers, in Canberra Times. 2013: Canberra, ACT.

53. Christopher Stone Bang for our bucks. False Economies, 2013.

54. OECD, Taxing wages: Country note for Austra lia, Development, O.f.E.C.-o.a., Editor. 2011, OECD Publishing: Paris, France.

55. Public Service Commissioner, Australian Public Service Commissioner's Directions 2013, in F2013L00448, Cabinet, D.o.P.M.a., Editor. 2013, Commonwealth of Australia: Canberra, ACT.

56. APS Commission. APS Statistical Bulletin. 2013 [cited 201423 January]; Available from: http://www.apsc.gov.au/about-the-apsc/parliamentary/apsstatistical-bulletin.

57. APS Commission. Australian Public Service Employment Database internet interface (APSEDii). 2014 [cited 201423 January]; Available from: https://apsc.gov.au/apsedii/APSEDIIFirstPage_index.shtm.

58. APS Commission. Gazette requirements. 20131 July [cited 201422 January]; Available from: http://www.apsc.gov.au/aps-employment-policy-andadvice/recruitment-and-selection/gazette. 